\title{
INTERVENÇÃO PEDAGÓGICA À LUZ DA ABORDAGEM COGNITIVISTA PARA ENSINO DE EDUCAÇÃO FINANCEIRA
}

\section{LUCAS MARIN BESSA}

Instituto Federal do Espírito Santo - Ifes

E-mail: lucas.bessa@ifes.edu.br

\section{ESTHER ORTLIEB FARIA DE ALMEIDA}

Instituto Federal do Espírito Santo - Ifes

E-mail: esther.ortlieb@ifes.edu.br

\section{RUtINELLI DA PENHA FÁVERO}

Instituto Federal do Espírito Santo - Ifes

E-mail: rutinelli@ifes.edu.br

\section{RESUMO}

A educação financeira é um assunto que ainda apresenta grandes desafios para sua disseminação no Brasil visto que, apesar dos esforços realizados nos últimos anos, ainda carece de estudos, principalmente quanto a discussões metodológicas e práticas de ensino. Pensando nisso, este estudo buscou descrever uma intervenção pedagógica em educação financeira a partir da abordagem cognitivista, em um projeto realizado no contra turno do período letivo de uma Instituição pública de ensino. Trata-se de uma pesquisa descritiva de natureza qualitativa e teve como procedimento de análise a observação realizada pelos mediadores, a partir dos dados colhidos por meio de questionários preenchidos pelos estudantes. Participaram da pesquisa estudantes de cursos técnicos integrados ao Ensino Médio de uma Instituição Federal de Ensino e teve como mediadores um Professor de Finanças e uma Psicóloga. Como resultados, a abordagem cognitivista foi positiva para a realização de iniciativas de educação financeira visto que o fato do professor se apresentar como mediador e o estudante como parte ativa no processo de aprendizagem possibilitaram a ressignificação do espaço escolar, do curso e de conteúdos estudados.

\section{PALAVRAS-ChAVE:}

Abordagem Cognitivista; Educação Financeira; Prática Pedagógica; Adolescente.

PEDAGOGICAL INTERVENTION IN LIGHT OF THE COGNITIVIST APPROACH TO FINANCIAL EDUCATION TEACHING

\section{ABSTRACT}

Financial education is a subject that still presents great challenges for its dissemination in Brazil since, despite the efforts made in recent years, it still lacks studies, especially regarding methodological discussions and teaching practices. This study sought to describe a pedagogical intervention in financial education from the cognitive approach, in a project carried out in the counter shift of the academic period of a public educational institution. It is a descriptive research of qualitative nature 
and had as an analysis procedure the observation carried out by the mediators, from the data collected through questionnaires filled out by the students. Students from technical courses integrated to high school at a Federal Educational Institution participated in the research and had as mediators a Finance Professor and a Psychologist. As a result, the cognitive approach was positive for the realization of financial education initiatives, since the fact that the teacher presents himself as a mediator and the student as an active part in the learning process enabled the redefinition of the school space, the course and the contents studied.

\section{KEYWORDS:}

Cognitive Approach; Financial Education; Pedagogical Practice; Teenager.

\section{INTRODUÇÃO}

A educação financeira, apesar de estar na mídia diariamente apresentada como um assunto de suma relevância para jovens, adultos e idosos, é citada apenas como tema transversal na atual versão da Base Nacional Curricular (BNCC) de 2017, o que dificulta a sua disseminação como conteúdo, visto que não apresenta, de forma clara, de que forma sua implementação deverá ser realizada.

Além disso, os efeitos esperados pelo Decreto Federal no 7.397/2010 que criou a Estratégia Nacional de Educação Financeira (ENEF), que visou a incentivar práticas de educação financeira, não parecem ser suficientes para a disseminação do conhecimento sobre o assunto. Para Vargas (2012, p. 21), que analisou a implantação da ENEF, "O projeto defendido pela ENEF surgiu para que, além do consumo, a população se torne investidora, e que exista o consumo consciente, para manter ou aumentar o crescimento do país, tão valorizado pelo Estado".

Ao analisar os dispositivos legais sobre o conteúdo das disciplinas obrigatórias do ensino fundamental e médio, mesmo quando observado o currículo do curso técnico de Administração, verifica-se apenas a menção sobre o ensino de juros simples e compostos dentre os conteúdos das disciplinas de Matemática e Finanças, algo insuficiente e que pouco acrescenta na reflexão sobre o uso desses conhecimentos para o dia a dia dos estudantes, visto que apenas ensina a mecânica do uso de fórmulas e a aplicação destas em problemas fictícios presentes nos livros didáticos. 
Somado a isso, os projetos isolados sobre finanças pessoais disponíveis na internet e em livros estão aplicados, muitas vezes, a uma realidade de pessoas que já têm conhecimento prévio na área e que, em sua maioria, já estão na maioridade, algo distante quando se analisa um estudante de quatorze a dezoito anos que está cursando um curso técnico integrado ao ensino médio. Acrescenta-se, segundo a Pesquisa Nacional de Endividamento e Inadimplência do Consumidor, realizada pela Confederação Nacional do Comércio de Bens, Serviços e Turismo (CNC, 2017), que $61,8 \%$ das famílias brasileiras estão endividadas e cerca de $26 \%$ apresentam dívidas ou contas em atraso. Além do mais, cerca de 4,81 milhões de jovens, entre 18 e 24 anos, estão inadimplentes no Brasil (SERASA, 2018), um quantitativo alto que necessita de iniciativas urgentes para sua mitigação desde os anos iniciais.

Pensando nisso, um Professor de Finanças do curso de Administração de uma Instituição Federal de Ensino resolveu unir os conhecimentos da sua área com o Setor de Psicologia da Instituição em que atua visando à criação do projeto "Educação Financeira: aprenda a lidar com seu dinheiro", ao perceber a necessidade de instrumentalizar os estudantes para o uso racional dos recursos financeiros, desenvolver práticas de autocontrole, discutir a importância de se poupar e, por fim, preparar os estudantes para a realização de investimentos. Esta parceria se justifica pois, segundo Piaget (1972/1996), o trabalho de cooperação entre a psicologia e as outras áreas do conhecimento faz-se necessário para uma melhor formação do estudante, enriquecendo as discussões em sala de aula, unindo as atividades de ensino e pesquisa, valorizando o trabalho dos profissionais das áreas integradas e tornando o estudante não apenas um receptor de conhecimentos que Ihes são transmitidos, mas sim ator e agente de cada conteúdo trabalhado. Além disso, o autor destaca que o desenvolvimento de práticas de ensino interdisciplinares faz com que o estudante tenha acesso ao conhecimento por diferentes pontos de vista, aumentando seu nível de compreensão do cotidiano e dos conhecimentos estudados. 
O projeto em questão teve seu início em 2015 com turmas compostas por estudantes finalistas do ensino médio técnico que, de forma voluntária, no contra turno das aulas e em caráter extracurricular, passaram um período aprendendo sobre o assunto. Os estudantes atendidos, em sua maioria, eram moradores da região Serrana do Espírito Santo e cidades limítrofes, sendo que muitos se mantinham financeiramente contando apenas com os proventos que recebiam das bolsas de auxílio advindas de recursos públicos, programas de estágio e monitoria, algo que aumenta, ainda mais, a relevância do projeto desenvolvido, visto que eles precisavam, além de realizar suas atividades, contribuir com o pagamento das contas de seus lares e se alimentar com esses recursos. Outras iniciativas também fizeram parte do projeto, tais como palestras de conscientização sobre o uso do dinheiro, minicursos e outras atividades que envolveram estudantes, familiares servidores e comunidade externa.

Apesar de terem sido realizadas diversas modificações no projeto nesses mais de 3 anos de existência, muitas delas motivadas a partir das respostas dos estudantes durante e após sua realização, o professor e a psicóloga, responsáveis pela iniciativa, sempre questionaram sobre a necessidade de aprofundar a prática docente, principalmente quanto às formas como os conteúdos eram trabalhados, a disposição física do ambiente de sala de aula, a forma de participação do estudante nas discussões e os métodos de avaliação utilizados, pois perceberam que era necessário dar ao estudante um papel mais ativo quanto aos conteúdos estudados, fatores esses que levaram à busca por conhecimentos relativos à abordagem cognitivista.

Assim, o objetivo da presente pesquisa foi descrever uma intervenção pedagógica em educação financeira sob a ótica da abordagem cognitivista, ocorrida em 2018 para estudantes dos Cursos Técnico de Administração e Agroindústria, com idade entre 14 e 17 anos. É caracterizada como pesquisa descritiva qualitativa e teve como instrumentos de análise a observação realizada pelos mediadores e questionários preenchidos pelos estudantes. 
Mediante tais considerações, a hipótese discutida é: o professor, em sua práxis docentes, aprimora sua prática pedagógica quando as interpreta à luz da abordagem cognitivista. Com isso, espera-se a construção de conhecimentos para compreender a prática docente e, também, implementar ações que possibilitem a construção de conhecimentos significativos aos estudantes quanto às questões de finanças pessoais, além de incentivar novas práticas de educação financeira.

\section{FUNDAMENTAÇÃO TEÓRICA}

Barbosa (2015) afirma que é necessário promover, com crianças e adolescentes, reflexões sobre educação financeira, dado que os mesmos estão entrando no mercado com dívidas muito altas, principalmente oriundas de compras realizadas com cartões de crédito. A autora acrescenta, ainda, que o mercado de livros sobre educação financeira destinado a pais e familiares ainda é pequeno, mas está em amplo crescimento nas livrarias físicas e virtuais.

Em estudo sobre o assunto, Fajardo (2011) apresenta o caso de um projeto que teve o apoio do Ministério da Educação (MEC) e que integrou 891 escolas públicas do país visando a ensinar jovens a poupar para realizar seus sonhos por meio do consumo consciente, alertando-os para os perigos provenientes dos altos juros e dos parcelamentos de faturas dos cartões de crédito. Esse projeto funcionou por meio de uma parceria entre a Comissão de Valores Mobiliários (CVM), o Banco Central e outros órgãos do Sistema Financeiro Nacional embasados na Estratégia Nacional de Educação Financeira (ENEF), com interesse de levar o assunto para as escolas e fazer com que o professor inclua os conhecimentos financeiros em suas atividades, unindo a teoria com a prática e incentivando o estudante a dar maior significado ao espaço escolar.

Alinhado a isso, Bessa e Ronchi (2017), em seu estudo onde apresentam os resultados da intervenção ocorrida no ensino de educação financeira e detalham as ferramentas desenvolvidas, com destaque para um método denominado 6Ps para 
auxílio na tomada de decisão, observam sobre os resultados alcançados nas atividades desenvolvidas. Na conclusão dos estudos, é apresentado o relevante impacto desse tipo de iniciativa, principalmente a partir do relato dos participantes quanto a importância dos conhecimentos para sua vida pessoal e familiar e o uso racional do dinheiro. Também, é destacado o potencial da atividade ser desenvolvida de forma interdisciplinar, nesse caso unindo a Psicologia e a área de Finanças.

Tendo em vista que a educação financeira se utiliza dos conhecimentos da matemática financeira e dos juros e que, em alguns currículos, é proposto o ensino das áreas em conjunto, alguns estudos abordam o ensino da matemática financeira e novas metodologias de ensino.

Alinhado a isso, em uma pesquisa na qual é proposta uma intervenção pedagógica no ensino da Matemática Financeira visando desmistificar a disciplina como algo distante da prática, Facchin e Passos (2012) afirmam em seus estudos que as disciplinas técnicas em um currículo de ensino médio devem aproximar a família do âmbito escolar e instrumentalizar os estudantes para que utilizem os ensinamentos em sua vida. Para os autores, cabe ao professor provocar isso nos estudantes por meio de um método investigativo e formativo, tendo em vista que as aulas se tornem um local mais agradável e para que ele entenda onde e quando poderá utilizar-se dos instrumentos aprendidos em sala de aula.

Bona e Barcelos (2013), também professores de Matemática Financeira, apresentam em seus estudos uma proposta realizada no Instituto Federal do Rio Grande do Sul e que teve resultados surpreendentes, quando analisado o ensino da matemática financeira por meio da utilização de planilhas e outros instrumentos tecnológicos, dado que os estudantes vivem em uma realidade de uso de tablets, celulares, computadores, notebooks, serviços em nuvem e muitas outras ferramentas que, se utilizadas para auxiliar na prática de ensino-aprendizagem, podem tornar 
disciplinas, que antes apresentavam alguma resistência de aceitação por parte dos estudantes, produtivas e interessantes. Para os autores, deve-se ressaltar a importância da matemática financeira para a vida pessoal e a formação do cidadão, pois, mesmo esta tendo sua origem no comércio, nos dias atuais este assunto aparece cada vez mais nas relações financeiras e econômicas da sociedade moderna, nos atos de comprar, negociar ou vender.

O papel do professor no processo de ensino-aprendizagem é destaque nos estudos anteriormente apresentados. De acordo com os Parâmetros Curriculares Nacionais (PCNs):

O papel do professor nesse processo é, portanto, crucial, pois a ele cabe apresentar os conteúdos e atividades de aprendizagem de forma que os alunos compreendam o porquê e o para que do que aprendem, e assim desenvolvam expectativas positivas em relação à aprendizagem e sintam-se motivados para o trabalho escolar (BRASIL, 1997, p. 48).

Assim, é de suma importância que o professor desenvolva sua prática pedagógica ciente da importância desta para a sua vida e para o processo formativo dos estudantes, principalmente quanto às questões reflexivas visando ao aumento da criticidade e tendo em vista incentivá-los a tornarem-se mais conscientes e racionais, sendo uma das abordagens alinhada a esses pressupostos a cognitivista.

A abordagem cognitivista tem como ponto crucial a investigação, levando o estudante ao processo investigativo para dar significado àquilo que aprende em sala de aula e nos espaços de discussão do saber, sendo o conhecimento algo em construção contínua, visando a desenvolver a inteligência do indivíduo (PASSOS, 2014).

Em seus estudos, Piaget (1972/1996) e Mizukami (1986), destacam principalmente quanto à relação professor-aluno em um ambiente de livre cooperação, devendo o professor ter um papel de orientação, bem como promover atividades desafiadoras, provocando desequilíbrios. Dessa forma, cabe ao professor evitar a rotina não se colocando como o detentor das respostas, devendo, sim, propor 
problemas e solicitar aos estudantes que os solucione, desafiando-os para que se tornem o mais independente possível, sendo que essa relação precisa ser afetiva e respeitar as regras do grupo, previamente estabelecidas no espaço de sala de aula (PASSOS, 2014).

Quanto ao processo avaliativo, na abordagem cognitivista as avaliações qualitativas devem estar presentes a todo momento, sendo que o estudante, além de participar do processo avaliativo, precisa demonstrar que assimilou o conteúdo e consegue realizar as operações e relacioná-las com o seu cotidiano, devendo-se ter como base para consolidação destas aprendizagens vários critérios de avaliação (PASSOS, 2014).

Por isso, apoiado nas discussões do papel do professor no processo de ensinoaprendizagem, na importância dos conteúdos serem significantes para a vida cotidiana dos estudantes e da necessidade do ensino de educação financeira nas instituições de ensino, tem-se na abordagem cognitivista uma forma de repensar as práticas tradicionais de ensino.

\section{METODOLOGIA}

\subsection{Metodologia DA PESQUISA}

Trata-se de uma pesquisa descritiva de natureza qualitativa, desenvolvida em um contexto escolar, no campus do Instituto Federal do Espírito Santo e contou como responsáveis um Professor de Finanças e uma Psicóloga que, a partir da análise cognitivista, realizaram intervenções em uma prática pedagógica de educação financeira. Como instrumentos de coleta de dados, foram utilizadas as técnicas de gravações de áudio, aplicação de questionários e anotações realizadas em diário de campo pelos mediadores ao final de cada encontro.

Acrescenta-se que, durante e após a realização do projeto, os estudantes foram convidados a responderem a questionários relatando aspectos sobre a forma como o 
projeto foi ofertado, a carga horária utilizada, a postura dos mediadores, como avaliavam o processo de ensino-aprendizagem, além de questões ligadas a impactos do projeto em suas vidas, tais como maiores dificuldades e facilidades que tiveram na aplicação do que aprenderam no dia a dia, sugestões e críticas.

Ressalta-se que, em nenhum momento, os estudantes participantes das pesquisas realizadas foram identificados, dado que não interessava para os extratos deste estudo identificar os respondentes, mas os impactos o projeto provocou em suas vidas e como a forma e o conteúdo apresentados, a partir da abordagem cognitivista, impactaram ou não seu comportamento de consumo. Destaca-se que a pesquisa foi aprovada pelo Comitê de Ética em Pesquisa sob o número 86706418.0000.5072 em julho de 2018.

Para análise, os dados das anotações, gravações de áudio e resposta dos questionários foram descritos e tabulados, observando a bibliografia existente para fins de análise e discussão.

\subsection{Metodologia de ENSINO}

A prática pedagógica foi realizada com 35 estudantes, com idade entre 15 e 17 anos, do curso técnico integrado ao ensino médio de uma instituição de ensino pública federal e foi desenvolvida por um professor de Finanças e uma psicóloga, os responsáveis pelo projeto. Desenvolvida no contraturno das aulas e em caráter voluntário, o projeto de Educação Financeira teve sua divulgação feita por meio de cartazes contendo um site para inscrição, um contato de e-mail para dúvidas, além de avisos que foram feitos pelos mediadores nas turmas ressaltando os conteúdos a serem trabalhados no projeto.

No momento da inscrição no projeto, os participantes responderam a um questionário online quanto a sua expectativa para o projeto, se trabalham ou participam de alguma iniciação científica, suas fontes de renda, gastos diários, o que 
fazem com seus recursos financeiros e questões sobre ansiedade, objetivos futuros e felicidade.

Os encontros foram desenvolvidos em um ambiente amplo e arejado, com recursos multimídia, quadro para anotações e outros recursos de apoio. Para esta atividade preferiu-se a utilização de um espaço que não fosse a sala de aula, visando a encurtar a distância entre professor e estudante, tradicionalmente comum a tal espaço. Também, não se nomeou as atividades do projeto com o termo "aulas" mas sim "encontros" e, logo no primeiro encontro, os responsáveis se apresentaram como "mediadores" e facilitadores do conhecimento.

Cada encontro teve duração de 90 minutos, além dos 30 minutos anteriores e posteriores ao projeto que foram disponibilizados para esclarecimento de dúvidas, apresentação de atividades em grupo e leitura dos materiais disponibilizados para consulta. Os encontros foram desenvolvidos da seguinte forma:

No primeiro encontro, foi realizada a apresentação do projeto pelos mediadores e a forma de avaliação proposta. Nesse encontro, objetivou-se tratar das questões lúdicas sobre o dinheiro e os anseios dos participantes quanto ao Projeto.

No segundo encontro, foram discutidos assuntos relacionados à ansiedade e consumo, com diversas intervenções da psicóloga que acompanhou as atividades do projeto. Além disso, uma planilha de orçamento pessoal foi disponibilizada para utilização, a qual poderia ser baixada em computadores e smartphones, e que seria apresentada de forma detalhada no terceiro encontro. Acompanhando o cronograma apresentado no primeiro encontro, foram sorteados temas divididos em 5 grupos contendo todas as áreas discutidas no projeto para que os estudantes realizassem a atividade de conclusão do projeto. Os grupos tiveram os seguintes temas: Grupo 1: Apresentação do projeto. Conceito de Educação Financeira. Emoções e consumo; Grupo 2: Planilha de controle de gastos. Cortes de gastos; Grupo 3: Investimentos em 
renda fixa; Grupo 4: Investimentos em renda variável; Grupo 5: Modelo 6Ps e autocontrole. Ressalta-se que em nenhum momento foi indicado qualquer tipo de apresentação para os participantes, apenas pontuadas questões quanto à importância de utilizarem uma linguagem acessível e exercitarem a criatividade, tendo único limitante o tempo de 15 minutos por grupo. Foi disponibilizado o local de realização do projeto para ensaios e confecção de material, caso fosse necessário. Por fim, com a utilização de um violão e slides com a letra e imagens sobre o conteúdo, foi interpretada uma música sobre consumismo.

No terceiro encontro, os mediadores abordaram conceitos financeiros e discutiram cada parte da planilha de orçamento pessoal apresentada no encontro anterior. Posterior a isso, uma atividade em grupo foi proposta visando a auxiliar um jovem que estava com suas contas negativas, tendo este personagem a mesma faixa etária dos estudantes do projeto, com projeto de vida e gastos parecidos com a realidade relatada pelos participantes. Ao final do encontro, cada grupo apresentou suas conclusões e pontuações sobre os cortes necessários para que o jovem ficasse com suas contas superavitárias.

No quarto encontro, foram discutidas questões sobre cortes de gastos e questões relacionadas à felicidade e à propaganda. Uma atividade em grupo também foi desenvolvida para que fossem discutidos charges e textos, que foram entregues pelos mediadores, devendo cada grupo discutir entre si o que entendiam e, após, apresentar suas conclusões. Ao final, os participantes foram convidados a realizar a avaliação parcial do projeto por meio de formulário eletrônico.

No quinto encontro, foram apresentadas questões sobre investimentos e a importância da prática da leitura para se desenvolver nessa área. Fez-se, também, uma explicação sobre o funcionamento do Sistema Financeiro Nacional e suas particularidades. Por fim, foi realizado um jogo por meio de um aplicativo de 
smartphone contendo os tópicos abordados até o momento no projeto, o qual pôde ser feito individualmente ou em grupo;

No sexto encontro, discutiu-se conceitos e tipos de títulos de renda fixa, além da apresentação de como é feita a tributação dos investimentos e suas particularidades.

No sétimo encontro, os participantes foram divididos em grupos para uma atividade de simulação de investimento em renda fixa para diferentes perfis de investidor. Posterior a isso, apresentou-se o conceito de carteira de investimentos e distinguiu-se as características dos investimentos de renda fixa e renda variável.

No oitavo encontro, os diferentes tipos de investimento de renda variável foram apresentados, além de realizada uma atividade, em grupos, de simulação para cada perfil de investidor. Outro assunto abordado foi o autocontrole e consumo consciente, assunto este que foi acompanhado pela metodologia dos 6Ps (BESSA e RONCHI, 2017), e por discussão com os participantes. Ao final, a partir das solicitações realizadas pelos participantes no formulário parcial, foi realizado um café compartilhado.

No encontro com pais e responsáveis, ocorrido no período noturno no auditório da instituição de ensino, os 5 grupos tiveram 15 minutos para realizarem suas apresentações com a possibilidade de utilização de recursos multimídia. O conteúdo das apresentações e o material foi apresentado de forma inédita para todos os presentes, inclusive para os mediadores, que deixaram a cargo dos participantes de cada grupo os recursos e conceitos utilizados, dando autonomia total para os participantes, acompanhando os conhecimentos defendidos pelos autores da abordagem cognitivista. Ao final do encontro, pais e responsáveis foram convidados a avaliarem o projeto e o impacto do mesmo nas atividades dos jovens no dia a dia em seus lares. Os estudantes também foram convidados a realizar a avaliação do projeto e destacar o impacto do mesmo em suas vidas. 
Durante toda a realização do projeto, a avaliação dos estudantes apresentou caráter formativo, visando a identificar a construção do conhecimento dos participantes. A proposta foi de que o estudante que cumprisse todas as atividades, individuais e em grupo e participasse ativamente dos encontros e das discussões seria avaliado como "Satisfatório" e receberia o certificado. Assim, aquele que não realizou as atividades propostas e não participou nas atividades de reflexão foi avaliado como "Insatisfatório", não recebendo o certificado. Ademais, foi avaliada a participação nos encontros, com o mínimo de $75 \%$ de presença para o recebimento do certificado, que teve como carga horária um total de 15 horas.

\section{RESUltAdOS E DisCUSSÃO}

\subsection{CARACTERIZAÇÃo dOS PARTICIPANTES}

Do total de participantes do projeto, $62 \%$ eram estudantes do curso técnico em Administração e 38\% de Agroindústria. A participação dos estudantes de Administração foi maior, tendo em vista que muitos já tinham algum contato com os assuntos abordados no projeto, o que pode tê-los motivado significativamente. Ressalta-se que o fato dos estudantes participantes fazerem parte de diferentes cursos, turmas e níveis de ensino tornou-se um ganho para as discussões em sala de aula, pois alguns já haviam cursado as disciplinas relacionadas à matemática financeira e finanças, enquanto outros ainda estavam cursando-as nas primeiras disciplinas do ensino médio, trazendo visões e perspectivas diferentes para as atividades em grupo e as discussões gerais.

Do total de respondentes, apenas 5,5\% apontaram que trabalhavam e 14,5\% afirmaram receber bolsa; também, o mesmo montante afirmaram receber mesada, tendo nas bolsas de estudo e nos auxílios dos programas de assistência estudantil seus únicos proventos para manutenção de suas atividades na cidade em que estudam. Quando questionados sobre o que fazem com seu dinheiro ao receber, apenas $18,2 \%$ 
disseram priorizar poupar e outros $12,7 \%$ afirmaram que, quando se dão conta, o dinheiro já acabou. Além disso, cerca de 31\% dos respondentes afirmaram não planejar suas compras.

\subsection{Desenvolvimento do Projeto}

Desde o primeiro encontro, os participantes foram convidados a questionarem os mediadores a qualquer momento, algo que resultou em diversas pontuações sobre a realidade de cada um e enriqueceu as discussões realizadas. A metodologia de trabalho utilizada nos encontros foi recebida com surpresa por muitos, como, por exemplo, a liberdade para sair do local a qualquer momento para ir ao banheiro, beber água ou não participar daquele encontro caso não houvesse interesse no assunto, tendo apenas a penalidade de registro da falta e, consequentemente, isso impactar na avaliação final caso ele não participasse das atividades. Ressalta-se que poucas foram as vezes em que algum participante se ausentou da sala, o que demonstrou o quanto é importante refletir sobre as metodologias utilizadas no processo de ensinoaprendizagem, dado que a utilização da abordagem cognitivista, que valoriza a autonomia do estudante, tornou o ambiente mais propício para que os participantes pudessem alcançar os objetivos traçados pelos mediadores e enxergassem significado pessoal no que estavam estudando.

Convidou-se, também, todos participantes para se sentarem ao chão. Esse gesto foi intencional e significativo, dado que os encontros iniciais tinham como tema principal as discussões sobre o uso do dinheiro, a necessidade de poupar e outras questões tidas como difíceis e ruins, e a falta de conforto de sentar no chão utilizada como analogia para que todos entendessem o desconforto causado pela má utilização dos recursos e a necessidade de realizar reajustes, poupança e investimentos visando a ter um futuro mais confortável. 
Com intuito de facilitar as discussões e a participação de todos, os participantes foram convidados a sentarem-se em um círculo para que todos pudessem visualizar os mediadores e os demais participantes, transferindo para todos a necessidade de participação e tirando do professor a visão tradicional do detentor de conhecimento. Essa disposição em círculo também foi representativa, dado que as experiências, necessidades e anseios dos estudantes foram pauta de todos os encontros, características embasadas na abordagem cognitivista.

Além disso, diversas atividades de jogos e simulações foram realizadas no decorrer dos encontros, visando a dar ao estudante a possibilidade de resolver problemas e ter autonomia para buscar conhecimento nos diversos materiais disponíveis e nas discussões realizadas nos encontros.

Quando avaliado o primeiro encontro, percebeu-se que os presentes participaram de forma ativa, colocando questões que os afligiam sobre o uso dos recursos financeiros. Além disso, observou-se que os trabalhos em grupo e as discussões entre os participantes tornou o processo de ensino-aprendizagem uma construção conjunta, sem preocupação sobre o "certo" ou "errado", tão comum nas disciplinas da grade curricular, principalmente em disciplinas da área de finanças e matemática financeira, objetos de estudo do projeto.

O segundo encontro teve início com a divisão dos grupos por parte dos mediadores, o que fez com que muitos pudessem interagir com colegas de turmas, séries e cursos diferentes, resultando em maior integração entre os participantes, o que pôde ser observado quando realizadas as dinâmicas em sala de aula. Essa atividade teve como foco dar autonomia para que os estudantes pudessem desenvolver suas atividades em equipe e, também, criar um método próprio para apresentação dos conhecimentos obtidos no decorrer dos encontros para seus pais e responsáveis, com liberdade e sem a intervenção dos mediadores. 
Um violão foi utilizado para interpretar uma canção muito conhecida dos participantes que versa sobre ostentação e consumo, sendo esta apresentada sob um olhar crítico e com questionamentos sobre o conteúdo da letra, incentivando-os a que questionassem as estrofes escritas e vissem a música que cantavam com outro olhar observando cada parte da letra.

No terceiro e quarto encontros, ao inserir a planilha financeira de gastos e o preenchimento da mesma ser feito por cada um, o resultado encontrado na planilha levou muitos a pontuar suas surpresas quanto à quantia que seus pais necessitavam despender para manutenção dos lares e de suas vidas, o que levou alguns a afirmarem "eu estou quebrado", "eu não sabia que meu pai gastava tanto, liguei para ele após a planilha e pedi desculpas, prometendo economizar", demonstrando o impacto da atividade na vida de cada participante.

Quanto ao corte de gastos e a atividade em grupo para auxiliar um jovem que estava deficitário e que tinha uma realidade muito próxima a dos participantes do projeto, muitas soluções foram apresentadas, com alto nível de profundidade e, novamente, demonstrou a importância da integração de diferentes séries e cursos para o desenvolvimento das atividades. O desafio imposto pelos mediadores também fez com que muitos utilizassem seus smartphones e outros recursos visando a buscarem informações nos diversos sites indicados nos encontros anteriores.

Isso aproximou o estudante dos recursos que usam no dia a dia dando significado ainda maior nas discussões apresentadas no projeto, ressignificando o uso da tecnologia na resolução de problemas como ferramenta de suporte e auxílio, quebrando o tabu do uso de tecnologia no ambiente de sala de aula.

Como previsto no cronograma, um questionário parcial foi aplicado por meio eletrônico sem identificação visando a avaliar o conteúdo, a metodologia utilizada e as considerações sobre melhorias do projeto desenvolvido. Quanto à relação de 
proximidade que mantinham com os mediadores, além de questões quanto à produtividade dos encontros, os participantes afirmaram que o projeto estava sendo "agradável e produtivo" e destacaram "do jeito que o projeto é dado", "interação entre o professor e os alunos".

Sobre os recursos utilizados e estudos de caso, destacam-se as afirmações de que gostavam "dos estudos de caso, onde interagimos com os outros colegas e expomos nosso olhar crítico", "dos momentos em grupo, nos quais ajudam a ver a observação de várias pessoas ao mesmo tempo para ter uma conclusão", "gosto dos momentos em que discutimos sobre aprender a economizar pois cada um mostra suas ideias de como economizar". Observa-se que as falas apresentadas pelos estudantes vão ao encontro das pontuações relacionadas à abordagem cognitivista destacadas por Passos (2014), Piaget (1972/1996) e Mizukami (1986), principalmente quanto à relação professor-aluno em um ambiente de livre cooperação e o professor tendo um papel de orientação, bem como de atividades de desafio, provocando desequilíbrios.

Quanto ao conteúdo, diversas foram as declarações sobre a importância do projeto para suas vidas, dentre as quais: "o projeto está sendo ótimo para mim", "assuntos que o projeto trouxe e que não davam importância" e "(...) ampliação de conhecimento sobre o mundo e como lidar com problemas encontrados no decorrer da vida". Os participantes também foram convidados a avaliar os pontos de melhorias, sendo que alguns solicitaram que o tópico sobre uso dos recursos financeiros retornasse após as discussões sobre investimentos, fato este que foi observado e retomado no decorrer dos encontros, tirando as dúvidas dos participantes.

Um dos pontos criticados por boa parte dos estudantes foi a questão de sentar no chão, tendo diversas reclamações realizadas pelos estudantes no questionário. Isso provocou alteração no ambiente por parte dos mediadores a partir do quinto encontro, com a colocação de cadeiras dispostas em círculos e mantendo a 
metodologia utilizada, mas dando o conforto necessário para as atividades, atendendo uma reivindicação dos participantes para melhorar o processo de ensinoaprendizagem.

Do mesmo modo, foi pontuada a questão dos termos técnicos utilizados em algumas discussões sobre investimentos, dado que muitos afirmaram desconhecer muitos termos utilizados no decorrer dos encontros. Por fim, no campo das sugestões, a ideia de um café compartilhado foi pontuada por vários, algo que foi concretizado no último encontro.

No quinto encontro, o assunto 'investimento' foi acrescentado às discussões com a apresentação de sites e livros, além de outros materiais de consulta, tendo vários sido colocados dispostos sobre as cadeiras visando a incentivar a prática de leitura. Visando a atender a pontuação realizada nos questionários quanto a dúvidas nos termos utilizados, foi feita a indicação de um glossário virtual para consulta contendo os termos mais utilizados, facilitando o entendimento dos tópicos estudados. Um jogo realizado por meio de smartphones também foi utilizado ao final do encontro, o que aproximou os participantes da atividade, motivando-os a praticarem os assuntos anteriormente abordados no projeto.

No sexto e sétimo encontros, o tópico de investimentos tornou-se mais presente nas discussões, tendo diversas atividades desenvolvidas em grupo com simulações, criação de carteiras de investimento a partir dos assuntos abordados e considerações dos mediadores quanto a necessidades, prazos e objetivos dos investidores e as diversas dúvidas quanto a investimentos de renda fixa e variável, questões pessoais e familiares quanto ao uso dos recursos e diversas ponderações sobre autocontrole, ansiedade e dicas para economizar, consumo consciente e onde buscar material para enriquecer os conhecimentos. 
No oitavo encontro, questões relacionadas à renda variável, dúvidas e simulações fecharam a programação do projeto, além de um momento para que os participantes pudessem expor as dúvidas gerais, e posterior café compartilhado, como solicitado pelos mesmos no questionário parcial realizado.

No encontro realizado com pais e responsáveis, os grupos realizaram suas apresentações a partir das anotações realizadas e consultas feitas, com um resumo dos conteúdos estudados na forma de apresentações dinâmicas e exemplificadas com atividades interativas com o público presente. Em nenhum momento foram realizadas intervenções dos mediadores e todos os grupos abordaram os temas estudados com informações atualizadas, obtidas pelos mesmos a partir das consultas realizadas nos canais indicados pelos mediadores e outros encontrados pelos mesmos em suas buscas. Nesta atividade, cerca de $70 \%$ dos pais convidados estavam presentes, além dos representantes da diretoria de ensino da Instituição e do setor pedagógico.

Dada a metodologia de avaliação, todos os participantes inscritos cumpriram os objetivos traçados e foram aprovados, obtendo a certificação ao final. Isso também ficou visível após análise dos questionários dos participantes, tendo afirmações como "Achei interessante a proposta do curso e de como ela foi realizada", "Foi um curso muito importante para mim, que me fez pensar nas minhas atitudes em relação à parte financeira da minha vida".

Ao avaliarem alguns pontos do projeto em uma escala de 1 a 5 , sendo 5 'ótimo' e 1 'ruim', 92,1\% dos participantes declararam notas 4 e 5 para o local de realização do curso; 92,5\% pontuaram de 4 a 5 a interação com os mediadores; cerca de $89 \%$ deram notas 4 e 5 para as simulações realizadas; cerca de $96 \%$ deram nota 4 e 5 quanto à metodologia de ensino; 89\% pontuaram com 5 o tempo de duração do projeto em 90 minutos; e cerca de $90 \%$ deram notas 4 e 5 quanto à duração de 15 horas no total. 
Quanto à aprendizagem, 94\% destacaram com notas 4 e 5 . Visando a avaliar o projeto como um todo, na mesma escala, cerca de $70 \%$ deram nota 5 e $30 \%$ nota 4 , valores muito acima dos resultados encontrados nos cursos realizados anteriormente com metodologias de trabalho nos moldes tradicionais. Assim, os mediadores avaliaram que os resultados obtidos no projeto foram maximizados devido a utilização instrumentos tecnológicos utilizados pelos estudantes no seu dia a dia, disposição da sala em formato circular tirando do professor o papel de "possuidor" dos conhecimentos e atividades em grupo com desafios e realização de simulações, o que deu significado aos conteúdos estudados e maximizou o processo de autonomia do estudante e cooperação na busca de resultados significativos para cada um.

Ressalta-se que os participantes e seus responsáveis procuraram os mediadores durante e após a execução do projeto para conversar sobre assuntos relacionados a disciplinas do curso técnico, assuntos particulares sobre planos familiares e dúvidas quanto ao planejamento financeiro. Outro fator foi que os atendimentos realizados pelo Professor de Finanças na reunião de pais foram expressivamente maiores durante a execução do projeto, quando comparado com outros períodos. Isso demonstra que o projeto aproximou, também, as famílias com o espaço escolar, fator esse fundamental para que o processo de ensino-aprendizagem ocorra da melhor forma.

\section{CONCLUSÃO}

Com os resultados obtidos no decorrer dos encontros realizados, da análise das anotações dos mediadores, das avaliações dos estudantes realizada durante e após o projeto e da percepção dos pais e responsáveis, o desenvolvimento do projeto por meio da abordagem cognitivista demonstrou ser relevante e possibilitou maior impacto nas famílias, na vida dos estudantes e no desenvolvimento dos pais e responsáveis quando comparado com os projetos desenvolvidos em momentos anteriores nos moldes tidos como tradicionais. 
Destaca-se que a metodologia escolhida, com o formato de cadeiras em círculo, a não centralização do papel do professor como o detentor do conteúdo e as discussões que, muitas vezes, foram trabalhadas e respondidas em grupo demonstraram ser o grande diferencial da abordagem cognitivista, tendo o estudante grande destaque e importância quanto ao processo de ensino-aprendizagem.

Além disso, a implementação das práticas de integração e participação ativa demonstrou que o protagonismo do estudante e as atividades desafiadoras devem ser observadas nas atividades de ensino de educação financeira, algo possível tendo em vista a fase de implantação de práticas nas escolas, e que essas devem tornar-se ainda mais presentes nos próximos anos, devido ao aumento da população endividada e à necessidade de políticas públicas para conscientização da população quanto ao uso racional do dinheiro.

Os professores e responsáveis observaram impactos do projeto desenvolvido no comportamento em sala de aula e no dia a dia de vários participantes, tendo, em muitos casos, afirmações de ressignificação do espaço escolar e do curso que estavam frequentando. Também, alguns apontaram que os estudantes se tornaram mais interessados nos assuntos abordados em sala de aula e críticos quanto a questões relacionadas ao uso do dinheiro e outros assuntos relacionados.

Assim, quanto a hipótese de que o professor, em sua práxis docente, aprimora sua prática pedagógica quando as interpreta à luz da abordagem cognitivista, percebese que, a partir dos elementos apresentados pelos estudantes e pelos ganhos no processo de ensino observados no decorrer do estudo, pode-se afirmar que a mesma é verdadeira.

Por fim, a inserção da educação financeira como conteúdo obrigatório do ensino básico necessita ser operacionalizada no Brasil visto que possibilitará relevantes impactos na vida das pessoas, minorando os níveis de endividamento, significando o 
uso da matemática e juros nas situações da vida cotidiana possibilitando a construção de um País mais desenvolvido e sustentável.

\section{AgRADECIMENTOS}

Agradeço ao Instituto Federal do Espírito Santo e às orientadoras Esther Ortlieb Faria de Almeida e Rutinelli da Penha Fávero pelas diversas contribuições e dedicação para que a presente pesquisa se tornasse realidade. 


\section{REFERÊNCIAS}

BARBOSA, Glaucia Sabadini. Educação Financeira Escolar: planejamento financeiro. 2015. 129f. Tese (Mestrado em Educação Matemática) - Universidade Federal De Juiz de Fora, Juiz de Fora, 2015. Disponível em: <http://www.ufjf.br/mestradoedumat/files/2011/05/Disserta\%C3\%A7\%C3\%A3o_Gla uciaSabadini_20151.pdf>. Acesso em 17 de novembro de 2018.

BESSA, Lucas Marin; RONCHI, Juliana Peterle. Educação Financeira como Instrumento de Integração em uma Instituição de Ensino Profissionalizante. Gerais: Revista Interinstitucional de Psicologia, Belo Horizonte, v.10 n. 1, jan-jun, 49 - 58, 2017. Disponível em: <http://pepsic.bvsalud.org/scielo.php?script=sci_arttext\&pid=S198382202017000100006>. Acesso em 17 de Novembro de 2018.

BONA, Aline Silva de; BARCELOS, Nilo. Matemática Financeira: uma prática atrativa valendo-se da tecnologia digital. In: VI Congresso internacional de ensino da matemática. 2013. Rio Grande do Sul. Anais VI Congresso internacional de ensino da matemática. 2013. Comunicação Científica. Disponível em: <http://www.conferencias.ulbra.br/index.php/ciem/vi/paper/viewFile/873/625>. Acesso em 19 de Novembro de 2018.

BRASIL. Ministério da Educação. Base Nacional Comum Curricular - BNCC. Brasília, DF, 2017. Disponível em: $<$ http://basenacionalcomum.mec.gov.br/images/BNCC_El_EF_110518_versaofinal_si te.pdf>. Acesso em 23 de Novembro de 2018.

BRASIL. Lei no 9.394, de 20 de dezembro de 1996. Presidência da República. Casa Civil. Subchefia para Assuntos Jurídicos. Diário Oficial [da] República Federativa do Brasil. Poder executivo, Brasília, DF, 23 dez 1996. Disponível em: <http://www.planalto.gov.br/ccivil_03/leis/19394.htm>. Acesso em 20 de Novembro de 2017.

BRASIL. Decreto no 7.397, de 22 de dezembro de 2010. Presidência da República. Casa Civil. Subchefia para Assuntos Jurídicos. Diário Oficial [da] República Federativa do Brasil. Poder executivo, Brasília, DF, 23 dez 2010. Disponível em: <http://www.planalto.gov.br/ccivil_03/_ato2007-2010/2010/decreto/d7397.htm>. Acesso em 23 Novembro de 2017.

Brasil. Parâmetros curriculares nacionais: introdução aos parâmetros curriculares nacionais/Secretaria de Educação Fundamental. Brasília, DF: MEC/SEF, 1997. 126p. Disponível em: <http://portal.mec.gov.br/seb/arquivos/pdf/livro01.pdf>. Acesso em 25 de Novembro de 2017.

CNC. (2017). Pesquisa CNC de endividamento e inadimplência do consumidor: outubro de

2017.

Disponível

em: 
<http://cnc.org.br/sites/default/files/arquivos/analise_peic_outubro_2017.pdf> Acesso em 13 de novembro de 2017.

FAJARDO, Vanessa. Alunos aprendem a lidar com dinheiro em aulas de educação financeira: Projeto com apoio do MEC integra 891 escolas públicas do país. Um dos objetivos do programa é ensinar a poupar para realizar sonhos. Disponível em: <http://g1.globo.com/educacao/noticia/2011/06/alunos-aprendem-lidar-comdinheiro-em-aulas-de-educacao-financeira.html> Acesso em: 23 de novembro de 2017.

MIZUKAMI, Maria da Graça Nicoletti. Ensino: as abordagens do processo. São Paulo: Editora Pedagógica e Universitária, 1986.

PASSOS, Marise Lyra Silva. Avaliação Formativa na Educação a Distância: um modelo conceitual para apoio ao planejamento. Novas Edições Acadêmicas. 2014. p.256.

PIAGET, Jean. Para onde vai a educação? Livraria José Olympio editora, 13a edição, Rio de Janeiro, 1996. (Obra original publicada em 1972)

SERASA (2018). Número de jovens inadimplentes atinge 4,81 milhões de negativados entre 18 e 24 anos. Disponível em: <https://www.spcbrasil.org.br/wpimprensa/wpcontent/uploads/2018/02/Release-Inadimpl\%C3\%AAncia-PF-_-Jovens.pdf>. Acesso em 21 de agosto de 2018.

VARGAS, Paulo Roberto Ribeiro. Um estudo sobre educação financeira e instituição escolar. 2012. 121f. Tese de Doutorado - Unisinos. São Leopoldo - RS, 2012. Disponível em:<http://www.repositorio.jesuita.org.br/bitstream/handle/UNISINOS/4724/16e.pd f?sequence=1\&isAllowed=y>. Acesso em 17 de novembro de 2018. 